\title{
The Impact of the Double Reduction Policy
}

\author{
Jia $\mathrm{Li}^{1, \dagger}$, Xuqing $\mathrm{Li}^{2, \dagger}$, Anqi Shi ${ }^{3, \dagger}$, Qianhui Yang ${ }^{4, *}, \dagger$ \\ ${ }^{1}$ School of Computer Science and Cyber Security, Communication University of China, Beijing, 100024, China \\ ${ }^{2}$ School of International Studies, Guangdong University of Education, Guangzhou, Guangdong, 510800, China \\ ${ }^{3}$ School of Foreign Languages, Suzhou University of Science and Technology, Suzhou, Jiangsu, 215009, China \\ ${ }^{4}$ School of Physics and Communication Electronics, Jiangxi Normal University, Nanchang, Jiangxi, 330022, China \\ *Corresponding author. Email: 20152844@stu.nun.edu.cn \\ Those authors contributed equally.
}

\begin{abstract}
This paper mainly investigates the Double Reduction Policy. The main body part focuses on the background of the policy, the current impact of the Double Reduction Policy by microsystem and mesosystem, and the challenges of the Double Reduction Policy. Several findings are included in this study. As for the impact of the policy from the microsystem, the off-campus tutoring institutions are required to find a new direction. The reform of the school service has largely changed the way that students learn and develop, easing the burden of homework. In addition, parents gradually realize the significance of education is to help children grow healthily. From the perspective of the mesosystem, the relationship between off-campus tutoring institutions and families has been largely weakened while the family-school relationship tends to strengthen. As for the challenges that the Double Reduction Policy might bring, two possible challenges are considered in this paper. On the one hand, family education will receive more attention after the Double Reduction Policy was released, and children need parents to accompany them in their growth. On the other hand, the policy also challenges schools to return to the lead of education. The contributions made should be of wide interest, because this paper is a review of the current policy which still requires new and sufficient research to investigate and it presents the impact that the Double Reduction Policy has here and now and might have in the future.
\end{abstract}

Keywords: Double Reduction Policy, Chinese Education Reform, Chinese Educational Policy, Ecological Systems, Off-campus Tutoring Institutions.

\section{INTRODUCTION}

Chinese students have undertaken the burdens from homework and off-campus tutoring. "Neijuan", which means involution in English, is becoming a phenomenon in the whole society, where children and parents will involve them in a fierce but not so necessary competition in the education area. Based on this background, the Double Reduction Policy, a new policy that aims to ease the burden of excessive homework and off-campus tutoring, was born on July 24th, 2021.

To investigate the Double Reduction Policy, the paper is divided into the background, the current impact, and the challenges. The paper finds that the off-campus tutoring institutions are looking for a new direction, the schools are practicing the new form of education, and family education is gaining its importance. Furthermore, the relationship between off-campus tutoring institutions and families is weakened while family-school one is enhancing. At the same time, off-campus tutoring institutions and families are facing challenges.

\section{BACKGROUND OF THE DOUBLE REDUCTION POLICY}

\subsection{Background of Social Life}

\subsubsection{Heavy Academic Burdens on Students}

In recent years, the heavy academic burden has overwhelmed the childhood happiness of Chinese primary and secondary school students.

The results from the Program for International Student Assessment (PISA) show that Chinese students achieved first place in all three subjects. However, the 
number of time students spent on reading was also higher than the Organization for Economic Cooperation and Development (OECD) average of 44 hours per week, at 57 hours [1]. This figure illustrates that students are generally inefficient in their studies, essentially trading 'time' for 'grades'.

The massive burden of homework has led to students having to cut short their sleep to ensure they complete their assignments. $38 \%$ of primary and secondary school students go to bed later than required and $67 \%$ of them do not get the required amount of sleep [2].

Many Chinese teachers regard a large number of assignments as the main means of improving students' academic performance, but such teaching methods not only reduce the time for students' all-round development but also undermine their physical and mental health. Chinese students should not have to sacrifice their playtime to become more powerful "examination machines".

\subsubsection{Heavy Financial Burden on the Family}

The heavy academic burden not only affects the healthy growth of students but also causes problems for parents.

On the one hand, parents need to bear the burden of homework from school indirectly. Some tasks, which should be done by teachers at school, are shifted to parents. This consumes parents' time and energy excessively and even triggers disharmony in homeschool relations.

On the other hand, parents have to bear the high cost of off-campus education. In 2017, the Institute of Sociology of the Shanghai Academy of Social Sciences showed that off-campus tuition accounted for $62.4 \%$ of total family education expenditure, making it the largest education expenditure in households [3]. According to the 2019 Domestic Family Investment in Children's Education Survey released by 51job Company, a Chinese HR service provider, $38.8 \%$ of surveyed families spend $20 \%$ to $30 \%$ of their annual household income on their children's off-campus education [4].

\subsubsection{Irregularities in Off-campus Tutoring Institution}

The total number of students participating in K-12 extracurricular tutoring in China has increased from 202.6 million in 2015 to 325.3 million in 2019. In 2018, the total number of compulsory education schools in China was 213,800 , but there existed 400,000 offcampus tutoring institutions, of which 273,000 were problematic [5]. In other words, the total amount of tutoring institutions has reached twice than it of compulsory education schools. If they are allowed to develop, they will form an educational system that is not conducive to the development of the national education system.

In addition, a large number of capitals have flooded into the training industry to make a profit. Many training institutions do not have educational qualifications, and illegal practices such as false propaganda and indiscriminate fees still exist. This kind of capitalisation of education goes against the public interest attribute of education and undermines the normal ecology of education in China.

\subsection{The Values of Education}

Under the pressure of seeking higher education in the country, students, parents, teachers, schools and tutoring institutions are beginning to be biased in their educational values. Words such as utilitarianism and comparing mentality have become buzzwords in discussions about the education industry. The focus of learning has shifted from learning knowledge points to learning question-answering skills, and students' views on learning have become utilitarian.

The root of the word 'educate', 'duct', means 'to guide', suggesting that education is about guiding a student's talents in a particular area so that they can become truly creative. Today's utilitarian values of education have seriously neglected the development of students' minds. This problem has significantly affected the continuation of the country's talent development and must be addressed.

\subsection{Political Background}

\subsubsection{The Need For A Three-child Policy}

According to the China Good Life Survey 2020 2021, "children's education" is the third most difficult issue for families after income and housing, indicating that education anxiety has become the most problematic topic for Chinese people [6]. Many people are reluctant to have children due to the huge cost of raising them.

China's seventh national census, which showed the total fertility rate reaching a historic low of 1.3 [7]. Against this backdrop, a major adjustment to China's fertility policy took place, shifting from a comprehensive two-child policy to a three-child policy. And it emphasises the need to implement supporting measures, one of which is to reduce the cost of childbirth, parenting and education [8]. Therefore, China needs some education policies to complement the three-child policy.

\subsubsection{The Quest For Education Equality}

Compulsory education in China has become largely universal, and the needs of the public show an 
escalation from having a school to having a good school. Families need quality and fair compulsory education and are willing to purchase off-campus education services to meet their children's educational needs for future development and self-fulfilment.

The public thought that the main problem with compulsory education in China was the "unfair distribution of educational resources, with large disparities between urban and rural areas, regions and schools" [9]. It can be seen that education equality is a basic demand of society at large for education.

\section{THE CURRENT IMPACT OF THE DOUBLE REDUCTION POLICY BY MICROSYSTEM AND MESOSYSTEM}

Drawing on the insights of Bronfenbrenner's ecological systems theory, children's development is influenced by the surrounding environment and social interactions within it. Bronfenbrenner divides the environment into five different levels: Microsystem, Mesosystem, Exosystem, Macrosystem, Chronosystem. The microsystem is the system that children make direct interactions with others including the proximity to home, school, tutoring institution, and community environment. The mesosystem is an interaction among two or more microsystems; for example, the interaction between off-campus tutoring institutions and family. The exosystem can indirectly affect the microsystem which then affects children; for instance, the neighbourhood and parent's workplace. The outermost system is a macrosystem that can impact all the systems such as economic, social, and political systems [10].

\subsection{Microsystem}

\subsubsection{Big Changes For Off-campus Tutoring Institution}

The Double Reduction policy for off-campus tutoring institutions can be broadly divided into three areas: new requirements for the approval of institutions, more regulation of the content and conduct of training, and increased efforts to regulate the operations of training institutions. All of these aspects are intended to prevent capital from coming down into the education sector to further exacerbate the academic pressure on students and aggravate "Neijuan".

This policy has triggered a chain reaction in the offcampus tutoring market: the share prices of listed K12 education institutions have plummeted, art training institutions are facing new opportunities, and teachers in the off-campus tutoring institutions have had to re-plan their future career development.

As a result of the Double Reduction Policy, the share prices of listed companies in China's off-campus tutoring companies have continued to fall. New Oriental plunged $54.22 \%$, TAL plunged $70.76 \%$, Gaotu fell $63.4 \%$, NetEase Youdao fell 42.8\%, 51Talk fell 43.3\% ..... The Big Three, TAL Education Group, Gaotu and New Oriental, have evaporated 800 billion yuan in market value from their highest point [11].

Enrolment in offline training courses at K12 tutoring institutions across the country has mostly been suspended. Online education companies such as Yuan Tutoring, VIPKID, Gaotu and many others have transformed their online education companies. Gaotu has now launched a new version of its APP, with training programs including language training, finance, management, medical and other types of vocational education [12].

Off-campus tutoring institutions have had to face layoffs. At the beginning of August, the education section of Bytespring had all been laid off. On September 10, 2021, the New Oriental Teacher Training Forum released the results of a research campaign on the current situation of teachers under the Double Reduction policy. The questionnaire, which collected 761 valid responses, surveyed teachers in the offcampus tutoring sector on their future career paths. The data shows that $38.90 \%$ of teachers would consider further education, $27 \%$ of teachers would consider joining a public or private school, and over $20 \%$ would consider switching to another profession [13].

Many training providers have started to give refunds to parents. As a result of the policy that subject-based training should not take up national holidays, rest days and the summer and winter holidays, most offline training courses were switched to online and their hours were adjusted from weekends to midweek evenings. With many students having conflicts with their school homework and a reduced level of concentration on online courses, many families have had to cancel training courses to ensure their children have to time off. But for some students with a talent for subjectbased competitions, the elimination of extensive subject-based training inevitably limits their development.

In contrast, quality education training in sports, programming and dance is becoming increasingly popular, allowing students to devote their free time to their hobbies and quality training. Wang believes that the sports training industry will maintain a general upward trend after the introduction of the Double Reduction policy such as the booming need of learning football in international education [14]. This is due to the increased weighting of sport in secondary school exams and the policy expectation that the inclusion of sport in the entrance exams will stimulate parents to place more emphasis on their children's participation in sport. The changes to the selection system provide a 
good basis for the further development of quality education.

Overall, students' weekends are no longer filled with traditional subject-based training and the further transformation of off-campus tutoring institutions provides more options for the all-round development of students.

\subsubsection{Public Schools and Teachers}

As the main front of public education, the position of public schools is undermined with the rapid rise in the private tutoring industry which is driven by marketization. Therefore, to strengthen the position of the school, the government has carried out school reform to improve school education quality which can help regain the trust and dependency of parents.

First of all, the schools should offer after-school services. According to the policy republished by the General Office of the Communist Party of China Central Committee (CPC), General Office of the State Council in 2021, schools under the compulsory education should offer after-school services when the formal classes are over; the services should not be over before local off-hours; Any curriculum-based lesson is forbidden during this time; Written homework should be finished during the service; Schools are encouraged to hold recreational and sports activities [15]. And the data from the Ministry of Education in 2021 showed that, up to 22nd September, there are $96.3 \%$ of schools have offered after-school services, $86.2 \%$ of teachers and $85 \%$ of all pupils have signed up for the service, about 206 thousand specialists outside of school have taken part in the service [16]. The service is widely covered all over the country in a short time.

During the services, study activities are held including doing homework, reading, etc. In addition, club activities, sports and art activities, as well as social practices, are also held.

The reform of the school service has largely changed the way that students learn and develop. With the help of after-school services, students can not only finish their homework in time with being supported by teachers and classmates but also can they take part in all sorts of activities including sports, arts, science, music and so on. Furthermore, in the past, students usually went home and did homework by themselves and doing homework would take up most of their time, replacing the time that they accompany with family members. Nowadays, they can improve their self-control when finishing their homework at school while strengthening cooperation and communication with others when taking part in activities. After going home, they have their own choices of how to spare the time. In this way, the school service reform could help students achieve all-round development.
In addition, the reform of schools can ease the burdens of doing homework. According to the policy republished by the General Office of the CPC Central Committee and General Office of the State Council in 2021, schools should improve homework management methods, strengthen overall planning, ensure the difficulty does not exceed the national curriculum, prohibit assigning homework to parents or demanding them to check homework, offer guidance on written homework at school [15]. As for the amount of homework, school is forbidden to assign written homework to grade one and grade two. The average writing time for grades three to six should not exceed 60 minutes, and that for junior high school should not exceed 90 minutes.

Murillo and Martínez-Garrido's research also showed that the time for doing homework has no impact on academic achievement while an appropriate amount of homework can improve it [17]. Therefore, for primary school students, less written homework is helpful for well-development physically and mentally with no need to worry about the decline in academic performance. For the advanced students, the burden of homework would also decrease while maintaining enough amount of homework for their academic goals.

\subsubsection{Family Education Receives More Attentions}

Family provides a foundation in which children learn how to navigate and fit into society. It is also the most intimate microsystem for children. After Double Reduction was published, the impacts on the family cannot be underestimated.

From the microsystem level, parents gradually realize the significance of education is to help children grow healthily instead of blindly pursuing high academic performance. A mother who was interviewed by Heilongjiang Daily indicated that before the Double Reduction policy was released, her son always complained that he was extremely tired. She said, "Before the introduction of the Double Reduction policy, I had to send my son to attend courses in many educational institutions on weekends. The weekends were filled with various discipline classes, and I often quarreled with my son. However, after this policy was released, I can finally spare the weekends to accompany my son. On the weekends, we often walk together in the park. I feel that the relationship between us is becoming better. She sighed that the Double Reduction policy helped her see the essence of education. "It is not advisable for parents to pay only money and brute force. The cultivation of good habits and high-quality company is what children need most and what family education should do most. " [18] 
Since parents are children's lifelong teachers, the formation of children's values, the shaping of personality and living habits are significant contents of family education, which cannot be replaced by school education

Family education should pay more attention to cultivating children self-learning abilities. After the Double Reduction was published, many parents wondered if the policy in the compulsory education stage would affect the competitiveness of children in their future careers. For this opinion, Yu gave her own opinion. She wrote, "The competitiveness of children in the future is not simply the solution of several problems, the most significant implication for children is not how much knowledge they have, but the self-learning ability. In other words, children must learn how to arrange learning plan by themselves, having a positive learning attitude and a good learning method is the right way." [18]

In addition, family education should comply with children's discipline of physical and mental development. Liu thought, "The Double Reduction Policy was not only to reduce the pressure on students' studies but also to change the concept of cultivating talents. Parents should return to 'people-oriented' and comply with the natural law of children's physical and mental development."

The principles of pedagogy put forward that education should follow the stages of children's physical and mental development. For example, Piaget's cognitive development stage theory pointed out that children had different physical and mental characteristics at different ages, education should follow the physical and mental characteristics of children at different stages of development, and educational contents and methods should be appropriately adjusted according to children's physical and mental characteristics because human growth process proceeds in an orderly way and step by step.

Moreover, effective communication is the key to family education. According to the research of the current situation of communication between contemporary middle school students and their parents. This survey interviewed 150 people which included 69 boys and 81 girls. The result showed that about $13.6 \%$ of children often communicate with their parents, $15.15 \%$ of children occasionally communicate with their parents, while most of the children were willing to communicate with parents [19]. Most of the interviewed children thought that parents can listen to their ideas and understand their requirements. Therefore, communication played an important role in family education.

\subsection{Mesosystem}

With the impact on the microsystem made by the Double Reduction Policy, the mesosystem which involves the interactions between microsystems has also been affected.

In the mesosystem of off-campus tutoring institutions and families, the strong interrelationship has been weakened to a large extend. Before the release of the Double Reduction Policy, due to the compulsory education and the widespread of high school education, the primary and secondary school enrolment rate had been increasing gradually. With the large population, only high performing academic achievement can improve the availability of scarce high-quality educational resources. Supplementary tutoring in the marketplace may be more client-oriented than regular schooling [20]. To take training for exam-based skills, excess demand from families for off-campus tutoring surged.

After the implementation of the Double Reduction Policy, mass-tutoring companies are forbidden to offer curriculum-based service which was once the most popular field in the private tutoring sector. To save themselves, they began to shift into the stream of the non-curriculum field providing non-curriculum tutorials such as programming, art, music. For families with children, the demand for receiving quality-oriented education is not a necessity as it is not a component of the mainstream education system. Therefore, the interaction between off-campus tutoring institutions and family is no longer rigid, but rather flexible.

However, the requirement for extra curriculum tutoring still exists which is likely to fuel one-to-one tutoring or home-based tutoring offered by individuals. This has once happened in Korea. After private tutoring is banned, parents turned to the black private to meet their demand leading to an increase in price [21]. The symptom of this trend has occurred that the price of home-based tutoring is up to 20 thousand a month which is a relatively attractive salary for new graduates. Given the situation, the bond between family and individual teachers may be strengthened henceforth.

The mesosystem between school and family is what the government aims to improve. Zhang has surveyed parents' satisfaction levels at school [22]. In terms of the opinion on teaching, it showed that more than half of parents considered the academic burden are overloaded. With the Double Reduction Policy, the course load is effectively relieved as the amount as well as the difficulty of homework decreased. As for the relationships between parents and school, Zhang's research indicated that a large proportion of parents have little contact with teachers among which $22.3 \%$ nearly have contact [22]. This could end in a lack of indepth understanding of children in parents. Therefore, 
parents tend to evaluate children as well as teachers by one-folded assessment criteria simply relying on grade. This could lead to a misunderstanding that it is the school to blame which does not provide good enough education that their children perform badly. It can be concluded that most parents possess a subjective attitude towards education regardless of the real situation. Hence, the government is encouraging family-school relationships to improve the educational idea of parents which can better reach the goal of double reduction.

In general, the role of off-campus tutoring institutions has changed. It is no longer within the mainstream of compulsory education but rather as a supplement of extra-curriculum. The family-school relationship continues to be strengthened that the family will show more trust and dependency towards school.

\section{LIMITATIONS OF THE DOUBLE REDUCTION POLICY}

After the Double Reduction was released, the limitations are emerging as the times require. Challenges also abound in the face of families and schools. This section analyses the dilemmas faced by families and schools in the context of the Double Reduction Policy.

\subsection{The Shortage Of The Scientific Family Educational Concept}

By investigating the educational concept of contemporary post-80s and post-90s parents, the survey shows that when parents try to apply the scientificeducational concept into family education practice, they often feel more than willing but lack the power [23]. There are two main reasons as follows.

First of all, the identity of the parent is very special. Being a parent doesn't require a compulsory course or any professional qualification examination. Therefore, many parents of young children, need more experience in the actual parenting process.

Secondly, in the information age, although multichannel information access broadened people's understanding of an event, it also increased the workload of screening high-quality information.

Additionally, the survey shows that most of the scientific theoretical knowledge learned by parents comes from schools, which is related to the educational experience or educational background of parents. The higher the educational background, the more theoretical knowledge parents obtain. The knowledge reserve often directly affects a person's conceptual level. As a result, the more scientific and theoretical knowledge parents have about children's development, they will be able to view and evaluate their children's actual development level more objectively.
On September 26th, PengPai News had an interview with a primary school teacher, Xu Jiasheng, who was directly affected by the Double Reduction gave her feelings and opinions about what parents should do after the introduction of the Double Reduction policy. She argued that "First, parents should change the educational model and strive to improve their children's self-drive. Secondly, parents should give more company and enhance their sense of belonging to the family. Moreover, parents should correctly guide their children and properly arrange their children's spare time." [24].

As for family education, the Double Reduction policy may have its advantages and disadvantages. Returning to family education also means that parents should shoulder more responsibilities. Parents need to spend more time on their children. It can be said to be a challenge for families.

\subsection{Individualized School Education}

For school education, the introduction of the Double Reduction policy will change the existing order of education. It is both an opportunity and a challenge for school education to return to the lead of education.

$\mathrm{Li}$ and Tian argue that off-campus tutoring has its justification in meeting the individual learning needs of students [25]. Previously students at different levels were able to seek targeted tutoring in off-campus tutoring institutions, after the Double Reduction, students' need for remedial classes to enhance their shortcomings and strengthen their strengths will inevitably not be realized through the route of offcampus subject training. How school education can fill the gap left by the withdrawal of off-campus education is undoubtedly a major challenge for school education. For example, how to establish a system of individually differentiated school assignments to meet the individual learning needs of different students; how to ensure the quality of assignments while reducing the number of assignments, including the overall design of the vertical structure, difficulty structure, type structure and level structure of the content of assignments.

\section{CONCLUSION}

This paper reviewed the Double Reduction Policy by evaluating the background, impact and limitation. From the perspective of the microsystem, the off-campus tutoring industry is losing its momentum that it needs transformation to survive. On-campus, the reform that has taken place in school which aimed to ease the burden has reshaped how students learn and develop. In terms of family, family education is receiving more public attention that children need parents to accompany them in their growth. From the perspective of the mesosystem, the influence of off-campus tutoring institutions waned that the demand from parents is no 
longer rigid but rather flexible. On the contrary, school is gaining more dependency from parents that it is regaining its dominant role in mesosystem. In the future, follow-up policies and measures should be made to overcome challenges, such as how to improve school education to meet differentiated demands of students and how can parents carry out scientific family education. By analysing the policy through ecological systems, the changes in education ecology in China is presented with the implication of problems and challenges which need a fundamental change in the education sector.

\section{REFERENCES}

[1] TALIS 2018: Insights and Interpretations. Oecd.org. (2021). Retrieved 11 November 2021, from https://www.oecd.org/education/talis/TALIS2018_i nsights_and_interpretations.pdf.

[2] Three firsts! Latest PISA test results released. Moe.gov.cn. (2019). Retrieved 11 November 2021, from

http://www.moe.gov.cn/jyb_xwfb/s5147/201912/t2 0191205_410921.html.

[3] The current environment for minors' growth from the family parent-child relationship, parental education expectations. Jyb.cn. (2017). Retrieved 11 November 2021, from http://www.jyb.cn/zcg/xwy/wzxw/201712/t201712 06_867846.html.

[4] MileagePlus Releases the 2019 Survey on Domestic Families' Investment in Children's Education. Prnasia.com. (2019). Retrieved 11 November 2021, from https://www.prnasia.com/story/2472541.shtml.

[5] National Education Development Statistics Bulletin in 2018. Moe.gov.cn. (2019). Retrieved 11 November 2021, from http://www.moe.gov.cn/jyb_sjzl/sjzl_fztjgb/201907 /t20190724_392041.html.

[6] Z.Y. Zhang, Reconstruction and governance of public education system under the pattern of "double reduction". Chinese Journal of Education (09), 2021, pp. 20-26+49.

[7] W. Chen, China's low fertility rate and the threechild policy - an analysis based on data from the seventh national population census. Population and Economics (05), 2021, 25-35.

[8] The decision of the State Council of the Central Committee of the Communist Party of China on Optimising Fertility Policy for Long-term Balanced Population Development. Gov.cn. (2021). Retrieved 11 November 2021, from http://www.gov.cn/xinwen/2021-

07/20/content_5626190.htm.

[9] China Modern Education Development Index 70.0 in 2021: Reducing Students' Burdens, Chinese Parents' 'Education Heartache". (2021). Retrieved 11 November 2021, from https://www.chinaxiaokang.com.

[10] J. Egbert, M. Roe, Theoretical Models for Teaching and Research.

[11] With the "double reduction", what are the capital choices? (2021). Retrieved 11 November 2021, from https://baijiahao.baidu.com.

[12] Chengdu's education and training scene: both supply and demand are doing "multiple choice". (2021). Retrieved 11 November 2021, from https://finance.eastmoney.com/a/20210827206860 0242.html

[13] The current situation of teachers in the education and training sector under the "double reduction" policy. (2021) . Retrieved 11 November 2021, from https://mp.weixin.qq.com.

[14] After the "double reduction", can the sports training industry usher in better times. (2021) . Retrieved $11 \quad$ November 2021, from http://www.xinhuanet.com/mrdx/202108/24/c 1310144995.htm

[15] Suggestions on further reducing the burden of homework and off-campus training for students in compulsory education. (2021). Retrieved 11 November 2021, from http://www.gov.cn/zhengce/202107/24/content_5627132.htm.

[16] Circular of the General Office of the Ministry of Education on innovative measures and typical experience in promoting after-school services under compulsory education in some regions. (2021). Retrieved 11 November 2021, from http://www.moe.gov.cn/srcsite/A06/s3321/202106/ t20210621_539265.html.

[17] F. Murillo Torrecilla, C. Martínez-Garrido Homework influence on academic performance: A study of iberoamerican students of primary education[J]. Revista de Psicodidáctica, 2013.

[18] Y.F. Fan, Be a "Smart Parent" in a "Child Friendly" family - Family education under the Double Reduction Policy. Hangzhou, pp. 66-67. DOI:10.16639/j.cnki.cn33-1361/d.2021.18.021.

[19] Investigation and Analysis of the current situation of communication between contemporary middle school students and their parents. (2021). Retrieved 
$11 \quad$ November 2021, from

http://www.bjdcfy.com/html/8b/67/63279.html

[20] C. Chan, M. Bray, Marketized private tutoring as a supplement to regular schooling: Liberal Studies and the shadow sector in Hong Kong secondary education, in Journal of Curriculum Studies, 46:3, 361-388. DOI: 10.1080/00220272.2014.883553

[21] C. Hoon, C. Álvaro, Regulating private tutoring consumption in Korea: Lessons from another failure, in International Journal of Educational Development.

DOI: 10.1016/j.ijedudev.2016.03.002

[22] Y. Y. Zhang, Investigation and Research on Parents' Satisfaction with Schools in Compulsory Education stage (Master's Thesis, Hefei Normal University).

https://kns.cnki.net/KCMS/detail/detail.aspx?dbna $\mathrm{me}=\mathrm{CMFD} 201802 \&$ filename $=1018064836 . \mathrm{nh}$

[23] G.Q. Guo, Investigation and Research on the educational concept of "Post-80s" and "Post-90s" children's parents. (Educational observation) DOI:10.16070/j.cnki.cn45-1388/g4s.2021.40.003

[24] Mr Xu Jiasheng of Luqiao primary school: "What can parents do after Double Reduction?” (2021). Retrieved $11 \quad$ November 2021, from https://www.thepaper.cn/newsDetail_forward_146 76429

[25] R.H. Li, Y.Y. Tian, The Double reduction, let education return to the essence of nurturing. Educator, 2021, pp. 19-20. 